\title{
Electron Beam Application for Regeneration of Catalysts Used in Refinery Cracking Units
}

\author{
Fernando Mantovani Kondo ${ }^{1}$, Celina Lopes Duarte ${ }^{1}$, Ivone Mulako Sato ${ }^{2}$, Vera Lúcia Ribeiro Salvador ${ }^{2}$ and \\ Wilson Aparecido Parejo Calvo ${ }^{1}$ \\ 1. Radiation Technology Centre, Nuclear and Energy Research Institute, National Nuclear Energy Commission (IPEN-CNEN/SP), \\ Av. Professor Lineu Prestes 2242, 05508-000, São Paulo/SP, Brazil \\ 2. Chemical and Environmental Center, Nuclear and Energy Research Institute, National Nuclear Energy Commission \\ (IPEN-CNEN/SP), Av. Professor Lineu Prestes 2242, 05508-000, São Paulo/SP, Brazil
}

\begin{abstract}
A catalyst is a substance that alters the rate of a reaction. The process of catalysis is essential to the modern day manufacturing industry, mainly in FCC (Fluid Catalytic Cracking) process units. However, long-term exploitation of oil and gas processing catalysts leads to formation of carbon- and sulfur-containing structures of coke and dense products on the catalyst surface. They block reactive catalyst sites and reduce the catalytic activity. The main advantage of radiation processing by EB (electron beam) and gamma rays is chain cracking reaction in crude oil. Otherwise, under exposure to ionize radiation, considerable structure modification of equilibrium silica-alumina catalyst from FCC process may occur, in addition to the removal of impurities. The conditions applied in the irradiation range (20-150 kGy) of gamma rays and EB were not sufficient to alter the structure of the catalyst, whether for removal of the contaminant nickel, a major contaminant of the FCC catalyst, either to rupture of the crystalline structure either for the future reutilization of chemical elements. ATR-FTIR (Attenuated Total Reflectance-Fourier Transform Infrared Spectroscopy and EDXRFS (Energy Dispersive X-Ray Fluorescence Spectrometry) analysis were used to characterize and evaluate effects of radiation processing on equilibrium catalysts purification. To evaluate and comprehend the reactive catalyst sites, SEM (Scanning Electron Microscopy) and particle size distribution analyses were carried out.
\end{abstract}

Key words: EB, gamma rays, FCC process, regeneration of catalysts, silica-alumina catalyst.

\section{Introduction}

The attempts to apply gamma rays irradiation method to fuel processing have been performed for years. Recently, gamma radiation has been proved to be an efficient method to remove thiol-sulfur from the simulated oil, and only several kGy (kilogray) were needed to obtain over $90 \%$ of the removal efficiency when some additives were used. The gamma rays irradiation has been found to be able to decompose dibenzothiophene in the simulated petroleum successfully in our previous study. However, the employed irradiation dosage was rather high to allow about $60 \%$ of the conversion efficiency [1].

Corresponding Author: Fernando Mantovani Kondo, M.Sc., research field: applications of nuclear technology-radiation processing and radioisotope technology.
The irradiation would be applied during the process of distillation of petroleum. In this context there is still a very important component in the process may have its effect changed with the irradiation: the catalyst.

In the catalytic cracking process, also known as FCC (Fluid Catalytic Cracking), the load (gas oil from the vacuum distillation and would be used as fuel oil) comes into contact with a catalyst at an elevated temperature, occurring rupture (cracking) of molecular chains, giving rise to a mixture of hydrocarbons which are further fractionated. This process has as main purpose the production of LPG (liquefied petroleum gas) and/or naphtha. Meanwhile, products are formed heavier than naphtha and a high residual carbon content, called coke, which is deposited on the catalyst 
surface [2].

The ionize radiation impacting the sulfur components would then have a double positive aspect in both the decomposition of the oil components as in the coke deposited on the catalyst.

\section{Methods, Materials and Testing Procedures}

\subsection{Material}

The commercial FCC catalyst both virgin and exhausted used in petroleum refineries, which composition is mainly aluminum oxides, silicon oxide and aluminum silicate; nickel nitrate from Impex analytical grade, dichloromethane from Vetec also analytical grade, filter paper Whatman $42(15 \mathrm{~cm})$ and deionized water. A third sample of catalyst was prepared by contaminating the virgin catalyst with $3,000 \mathrm{ppm}$ of nickel.

\subsection{Radiation Processing}

The virgin and exhausted catalyst samples were irradiated at room temperature using a Cobalt- 60 Multipurpose Gamma Irradiator at absorbed doses of 20kGy, 50kGy, $100 \mathrm{kGy}$ and $150 \mathrm{kGy}$ and another batch of contaminated catalyst was irradiated at room temperature using an EBA (electron beam accelerator) Dynamitron DC1500/25/04, model JOB 188 at same doses.

\subsection{Chemical Processing}

The virgin catalyst was contaminated with 3,000 ppm of nickel following the Mitchell technique [3]. The contaminated batch was heated under reflux with dichloromethane as well as another contaminated batch irradiated with EB (electron beam) (20 kGy).

\subsection{Analysis}

The catalysts were first analyzed by ATR-FTIR (Attenuated Total Reflectance-Fourier Transform Infrared Spectroscopy) using an Perkin-Elmer Spectrum 100 to compare the influence of the gamma rays and also the EB effects on the structure of the catalyst.

Virgin, exhausted and after thermal treatment under reflux catalysts were analyzed by EDXFRS (Energy Dispersive X-Ray Fluorescence Spectrometry) using a Shimadzu Co., model Rany720 spectrometer.

All catalysts were observed with a SEM (Scanning Electron Microscope), model Hitachi Tabletop TM-3000.

\section{Results and Discussion}

Nickel and vanadium are the most relevant poisons for catalytic cracking catalysts so the virgin batch was contaminated to understand the irreversible contamination caused by nickel [4].

ATR-FTIR analysis has proved the irradiation with gamma rays on virgin and also exhausted catalysts did not change any molecular structure (Figs. 1 and 2).

The technique of SEM allows the initial observation of average grain sizes and shape (Figs. 3, 4 and5).

In Table 1 is shown the average particle sizes of virgin, exhausted, contaminated, contaminated and irradiated, contaminated and filtered catalysts.

The SEM (Figs. 3, 4 and 5) verified that the catalyst contaminated batches present larger grains started at the pre-sintering stage due to calcination at high temperatures. It is not possible to say that EB irradiation altered the shape or the average grain size, comparing the images obtained.

Considering all the SEM images, the clearest difference is presented by the exhausted catalyst; it was possible to verify holes and ruptures on the circular forms as well as the reduction of average grain size due the distillation process in refineries.

A batch of contaminated catalyst was washed four times with $20 \mathrm{~mL}$ of deionized water and filtered through Whatman $42(15 \mathrm{~cm})$ filter paper to check if the presence of soluble salts would alter the average grain size. The contaminated catalyst was heated with dichloromethane under reflux for 3 hours and 40 minutes to evaluate the effect of organic solvents in 


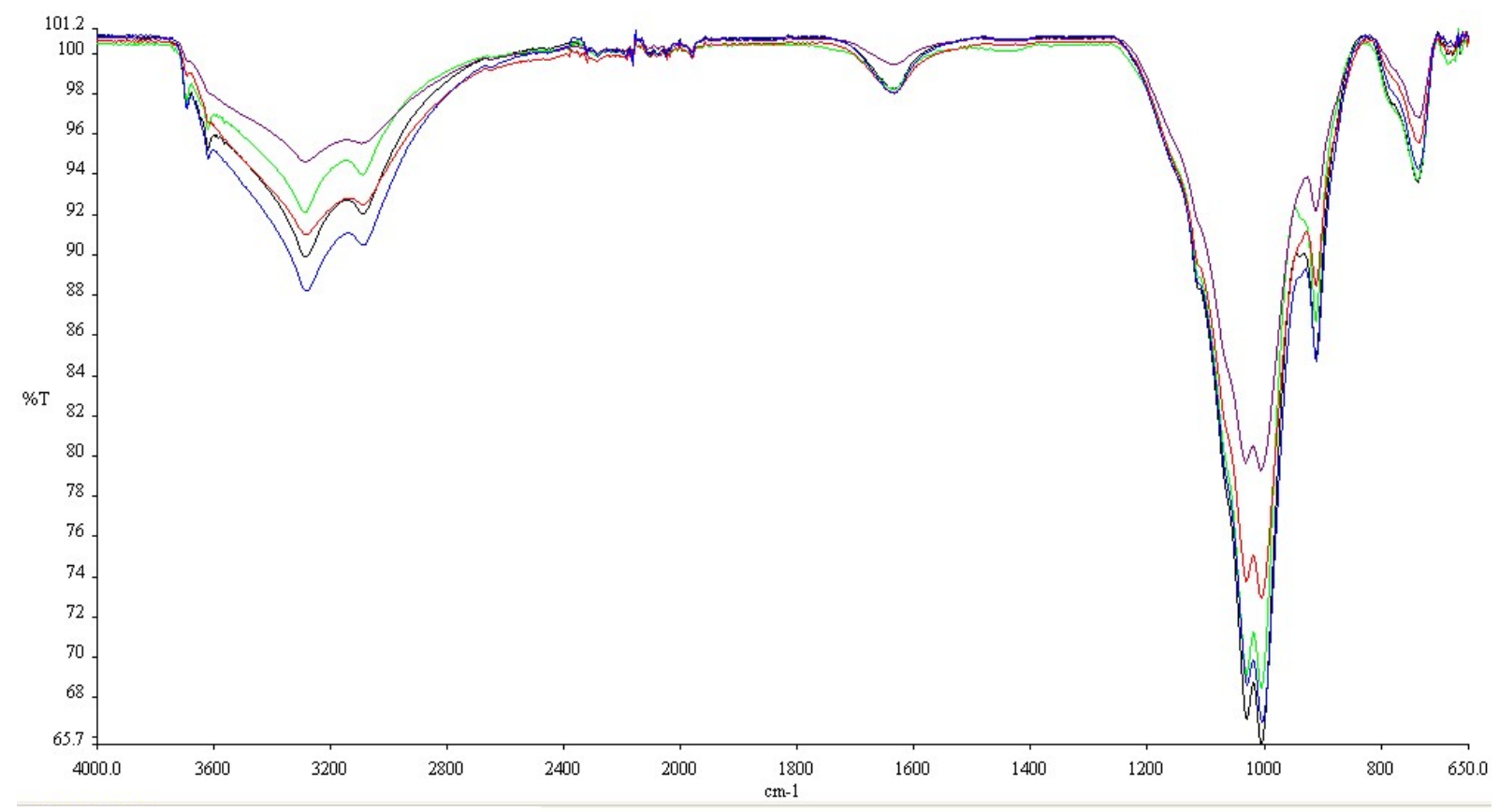

$\begin{array}{ll}\text { Cat } 1-\text { virgin } & \text { Cat1 }-100 \mathrm{kGy} \\ \text { Cat1 - 20kGy } & \text { Cat1 }-150 \mathrm{kGy} \\ \text { Cat } 1-50 \mathrm{kGy} & \end{array}$

Fig. 1 FITR spectrum of virgin and irradiated virgin catalysts with gamma rays.

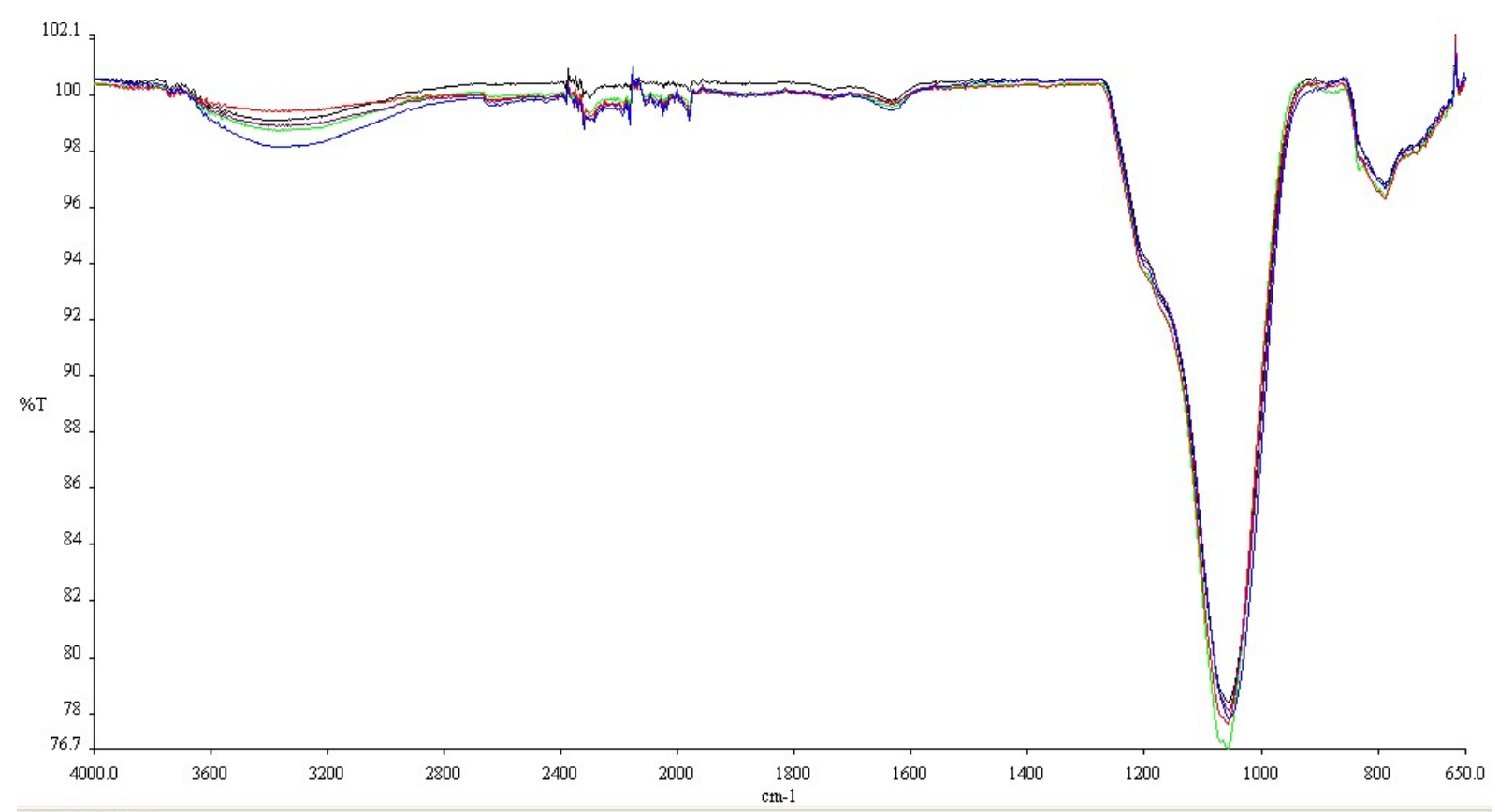
Cat2 - exhausted
Cat2 - $20 \mathrm{kGy}$
Cat2 - $50 \mathrm{kGy}$
Cat2 - $100 \mathrm{kGy}$
Cat2 - $150 \mathrm{kGy}$

Fig. 2 FTIR spectrum of exhausted and irradiated exhausted catalysts with gamma rays. 
Table 1 Catalyst average particle sizes.

\begin{tabular}{lll}
\hline Average particle sizes $(\mu \mathrm{m})$ & Min. & Max. \\
\hline Contaminated catalyst & 85 & 140 \\
Contaminated catalyst and irradiated at $100 \mathrm{kGy}(\mathrm{EB})$ & 77 & 125 \\
Filtered contaminated catalyst & 115 & 140 \\
Contaminated catalyst heated under reflux (3 h $40 \mathrm{~min})$ & 95 & 140 \\
Virgin catalyst & 110 & 140 \\
Exhausted catalyst & 75 & 110 \\
\hline
\end{tabular}

Exhausted catalyst

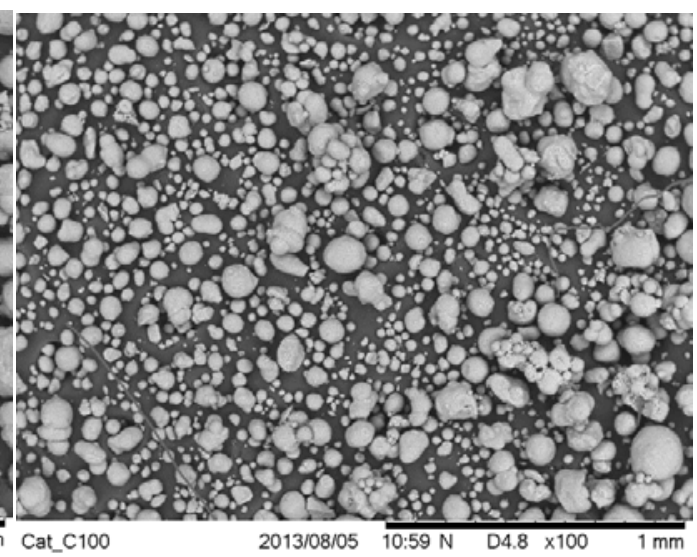

Contaminated catalyst and irradiated at $100 \mathrm{kGy}(\mathrm{EB})$

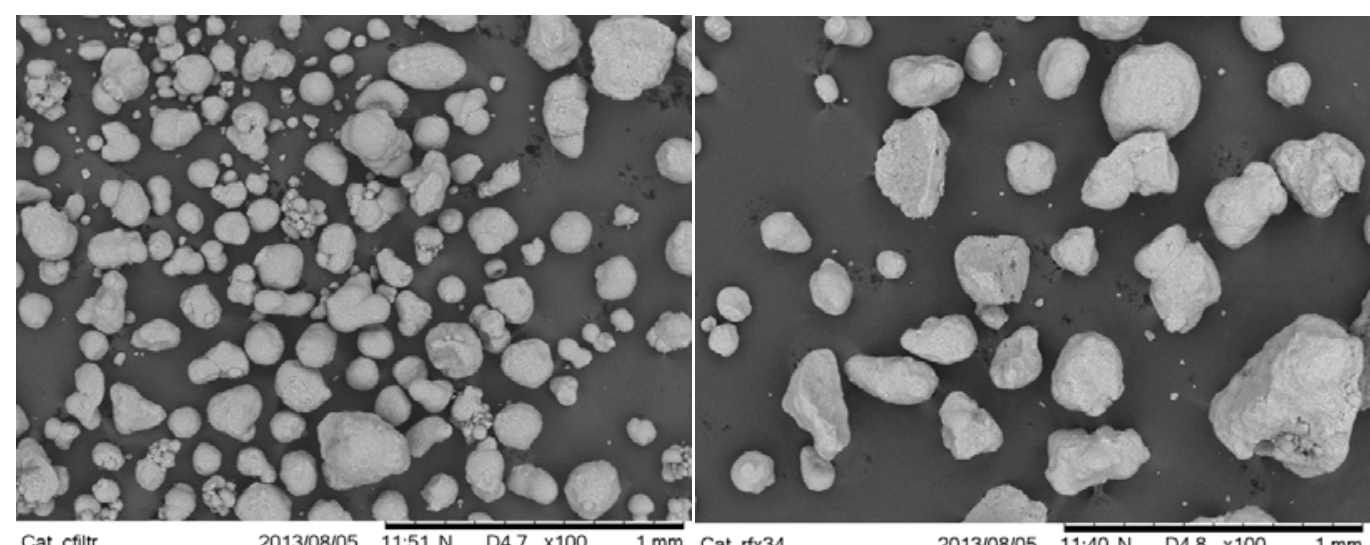

Filtered contaminated catalyst Contaminated catalyst heated under reflux ( $3 \mathrm{~h} 40 \mathrm{~min}$ )

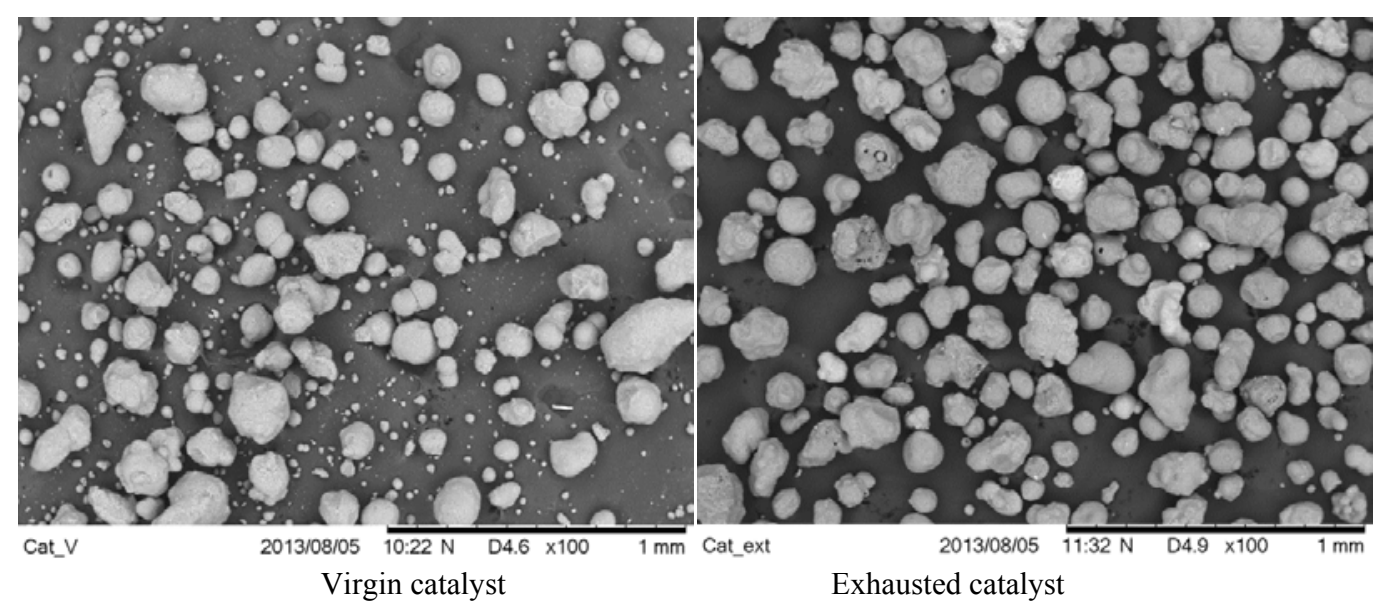

Fig. 3 Scanning Electron Microscopy $(\times 100)$. 


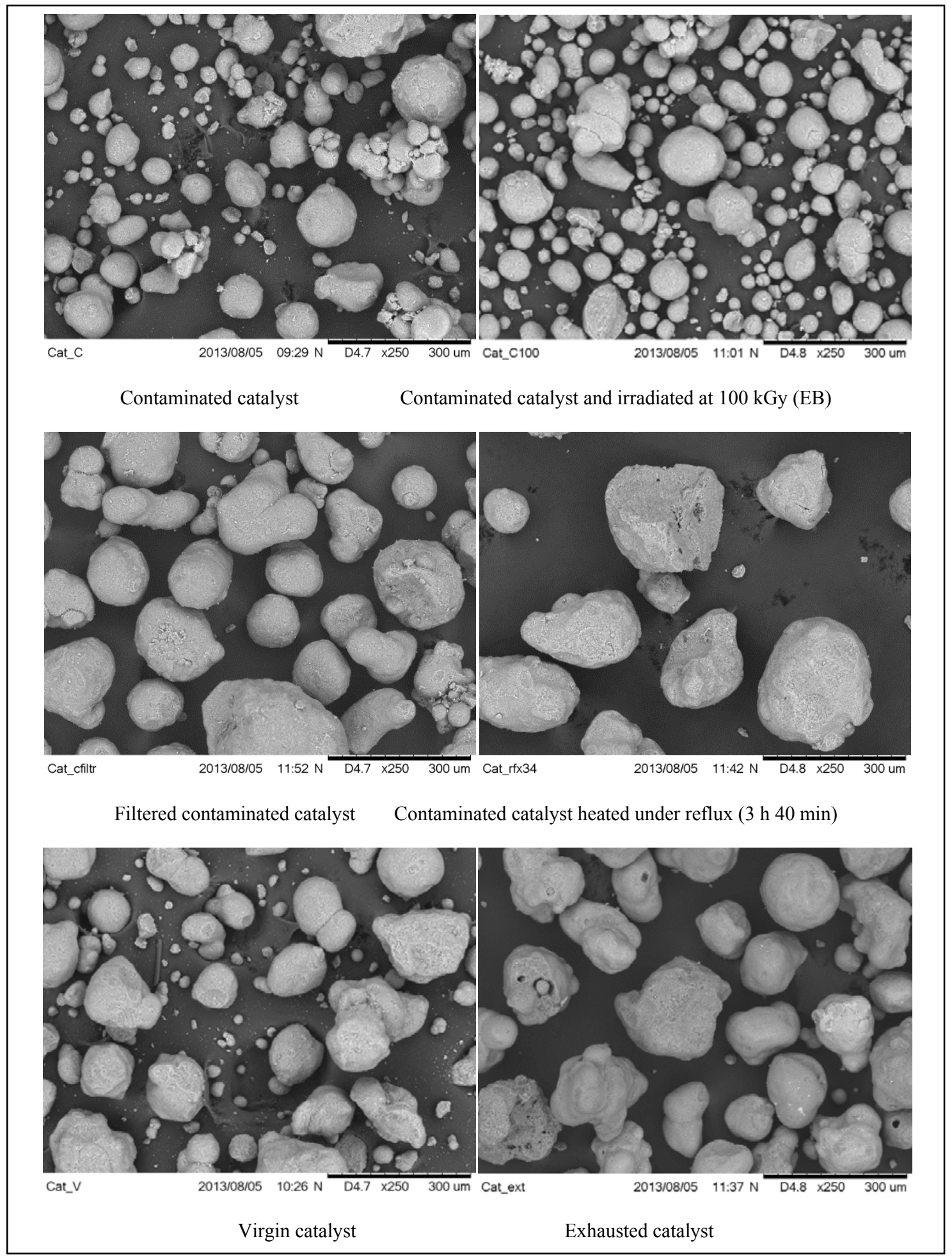

Fig. 4 Scanning Electron Microscopy (× 250). 


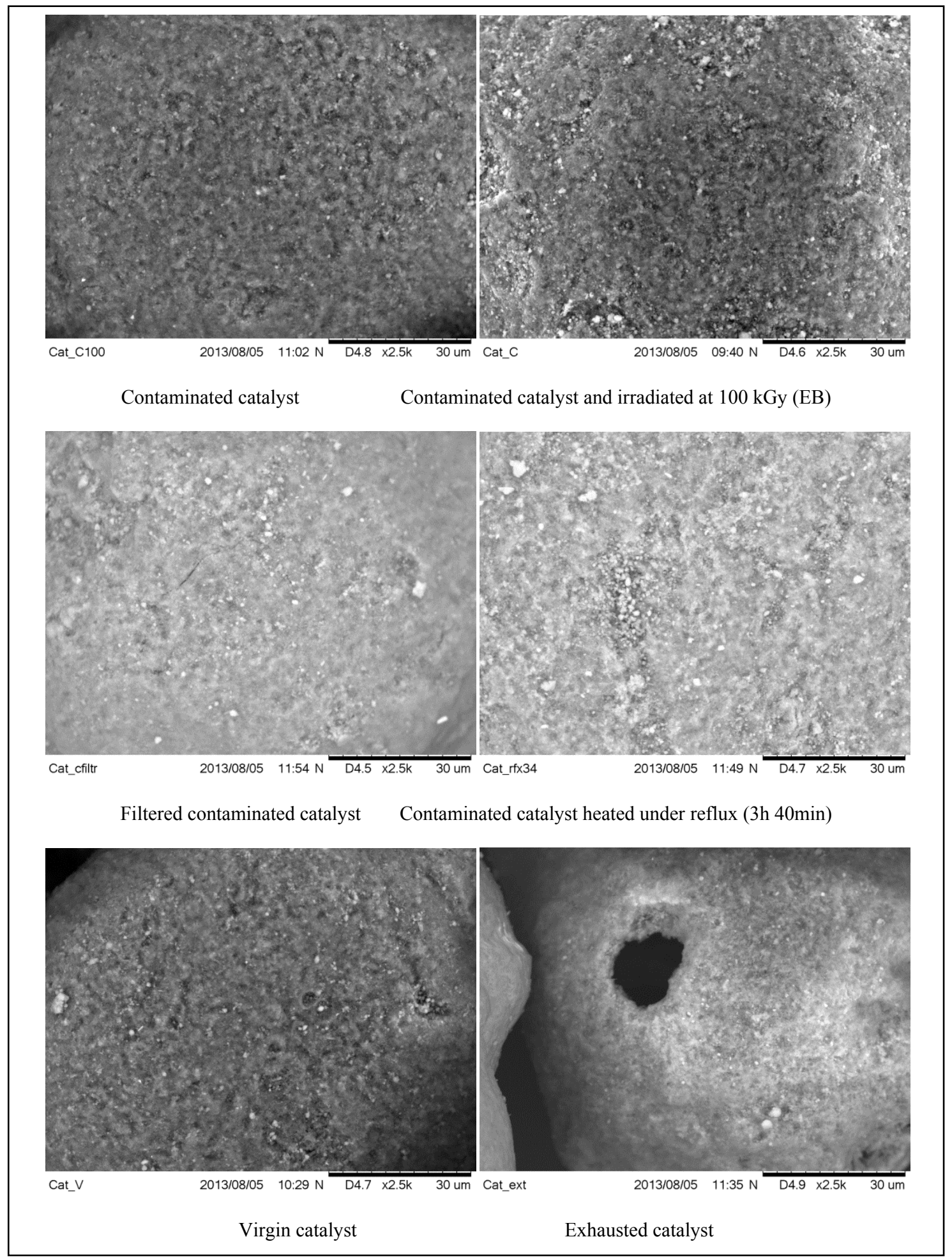

Fig. 5 Scanning Electron Microscopy $(\times 2,500)$. 
catalyst components. In both cases, the extraction of nickel contaminant was studied.

It was verified by EDXRFS (Energy Dispersive X-Ray Fluorescence Spectrometry) that nickel extraction was made more efficient by washing time with dichloromethane under reflux than with EB irradiation treatment.

Elemental determination using the EDXRFS spectrometry was performed at Chemical and Environmental Center (CQMA-IPEN/USP) using a Shimadzu Co., model Rany720 spectrometer, to understand if the irradiation by EB facilitates the removal of contaminating element (nickel), or if irradiation alters the catalyst structure to cause breakage which can be verified after-treatment heating under reflux.

The data obtained as shown in Tables 2, 3 and 4 illustrate that irradiation does not affect the binding of nickel on catalyst and that contaminant can only be released from the catalyst after washing, regarding the structure of the catalyst. It is found that the percentage of elements does not change significantly, indicating that EB irradiation does not cause breakage of the catalyst which could be verified by SEM or EDXRFS.

Analyzing the data from the EDXRFS is possible to assert that the nickel contamination was efficient comparing contaminated catalyst and irradiated at 20 kGy (EB) and virgin catalyst (Tables 2 and 3). However, the washing of the catalysts on which irradiated or not, does not have many differences, which becomes different when the washing time changes from 1 hour to 3 hours and 40 minutes. In this aspect the specified irradiation conditions do not alter the yield of purification catalyst.

Table 2 EDXRFS analysis in virgin catalyst versus exhausted catalyst.

\begin{tabular}{lll}
\hline Oxide & Virgin catalyst & Exhausted catalyst \\
\hline$\%$ & & \\
\hline $\mathrm{Al}_{2} \mathrm{O}_{3}$ & $60.9 \pm 0.1$ & $44.8 \pm 0.1$ \\
$\mathrm{SiO}_{2}$ & $35.3 \pm 0.1$ & $47.7 \pm 0.2$ \\
$\mathrm{La}_{2} \mathrm{O}_{3}$ & $2.06 \pm 0.03$ & $2.4 \pm 0.07$ \\
$\mathrm{Fe}_{2} \mathrm{O}_{3}$ & $1.04 \pm 0.02$ & $0.86 \pm 0.01$ \\
$\mathrm{SO}_{3}$ & $0.27 \pm 0.01$ & $0.18 \pm 0.02$ \\
$\mathrm{~K}_{2} \mathrm{O}$ & $0.185 \pm 0.004$ & $0.091 \pm 0.010$ \\
$\mathrm{~V}_{2} \mathrm{O}_{5}$ & $0.13 \pm 0.01$ & $1.7 \pm 0.3$ \\
$\mathrm{P}_{2} \mathrm{O}_{5}$ & - & $0.58 \pm 0.02$ \\
$\mathrm{CeO}$ & - & $0.40 \pm 0.03$ \\
\hline$\mu \mathrm{\mu g} \cdot \mathrm{g}^{-1}$ & & \\
\hline $\mathrm{CaO}$ & $235 \pm 22$ & $1,900 \pm 200^{*}$ \\
$\mathrm{MnO}$ & $143 \pm 22$ & $58 \pm 14$ \\
$\mathrm{ZrO}$ & $92 \pm 21$ \\
$\mathrm{Ga}_{2} \mathrm{O}_{3}$ & $103 \pm 21$ & $63 \pm 5$ \\
$\mathrm{CuO}$ & $79 \pm 15$ & $82 \pm 4$ \\
$\mathrm{ZnO}$ & $77 \pm 4$ & $122 \pm 7$ \\
$\mathrm{SrO}$ & $57 \pm 2$ & $102 \pm 5$ \\
$\mathrm{NiO}$ & $39 \pm 2$ & $10,400 \pm 200^{* *}$ \\
$\mathrm{Sb} \mathrm{O}_{3}$ & $14 \pm 7$ & $765 \pm 53$ \\
$\mathrm{Rb}_{2} \mathrm{O}$ & - & $10 \pm 2$ \\
$\mathrm{PbO}$ & - & $93 \pm 6$ \\
\hline $\mathrm{Nu}$ & - &
\end{tabular}

Number of repetitions $=3$;

- Undetectable;

* $1870 \pm 240 \mu \mathrm{g} \cdot \mathrm{g}^{-1}=0.187 \pm 0.024 \%$;

** $10370 \pm 200 \mu \mathrm{g} \cdot \mathrm{g}^{-1}=1.037 \pm 0.020 \%$. 
Table 3 EDXRFS analysis: contaminated catalyst irradiated at 20 kGy (EB) versus contaminated catalyst treated under dichloromethane reflux (1h).

\begin{tabular}{lll}
\hline Oxide & Contaminated catalyst irradiated at 20kGy $(\mathrm{EB})$ & Contaminated catalyst treated under dichloromethane reflux (1h) \\
\hline$\%$ & & \\
\hline $\mathrm{Al}_{2} \mathrm{O}_{3}$ & $60.6 \pm 0.3$ & $61.1 \pm 0.3$ \\
$\mathrm{SiO}_{2}$ & $38.5 \pm 0.2$ & $34.8 \pm 0.2$ \\
$\mathrm{La}_{2} \mathrm{O}_{3}$ & $1.43 \pm 0.03$ & $1.41 \pm 0.03$ \\
$\mathrm{Fe}_{2} \mathrm{O}_{3}$ & $0.95 \pm 0.01$ & $0.93 \pm 0.01$ \\
$\mathrm{TiO}_{2}$ & $0.87 \pm 0.03$ & $0.86 \pm 0.03$ \\
$\mathrm{NiO}$ & $0.542 \pm 0.006$ & $0.511 \pm 0.006$ \\
$\mathrm{SO}$ & $0.262 \pm 0.02$ & $0.264 \pm 0.02$ \\
$\mathrm{~K}_{2} \mathrm{O}$ & $0.14 \pm 0.01$ & $0.14 \pm 0.01$ \\
\hline$\mu \mathrm{g} \cdot \mathrm{g}^{-1}$ & & \\
\hline $\mathrm{CaO}$ & $209 \pm 50$ & $240 \pm 50$ \\
$\mathrm{ZnO}$ & $66 \pm 12$ & $73 \pm 10$ \\
$\mathrm{Ga}_{2} \mathrm{O}_{3}$ & $75 \pm 10$ & $73 \pm 10$ \\
$\mathrm{ZrO}$ & $133 \pm 8$ & $104 \pm 7$ \\
$\mathrm{SrO}$ & $39 \pm 6$ & $31 \pm 6$ \\
\hline
\end{tabular}

Table 4 Energy Dispersive X-Ray Fluorescence (EDXRFS) analysis: contaminated catalyst irradiated at 20 kGy (EB) treated under dichloromethane reflux (1h) versus contaminated catalyst treated under dichloromethane reflux ( $3 \mathrm{~h} 40 \mathrm{~min}$ ).

\begin{tabular}{lll}
\hline Oxide & $\begin{array}{l}\text { Contaminated catalyst irradiated at } 20 \mathrm{kGy}(\mathrm{EB}) \\
\text { treated under dichloromethane reflux }(1 \mathrm{~h})\end{array}$ & $\begin{array}{l}\text { Contaminated catalyst treated under dichloromethane reflux }(3 \mathrm{~h} 40 \\
\mathrm{min})\end{array}$ \\
\hline$\%$ & & \\
\hline $\mathrm{Al}_{2} \mathrm{O}_{3}$ & $60.9 \pm 0.1$ & $60.9 \pm 0.3$ \\
$\mathrm{SiO}_{2}$ & $34.8 \pm 0.1$ & $35.1 \pm 0.1$ \\
$\mathrm{La}_{2} \mathrm{O}_{3}$ & $1.45 \pm 0.03$ & $1.37 \pm 0.03$ \\
$\mathrm{Fe}_{2} \mathrm{O}_{3}$ & $0.94 \pm 0.01$ & $0.884 \pm 0.01$ \\
$\mathrm{TiO}_{2}$ & $0.87 \pm 0.02$ & $0.83 \pm 0.02$ \\
$\mathrm{NiO}_{\mathrm{SO}}$ & $0.521 \pm 0.006$ & $0.492 \pm 0.006$ \\
$\mathrm{KO}_{3} \mathrm{O}$ & $0.31 \pm 0.01$ & $0.32 \pm 0.01$ \\
\hline$\mu \mathrm{g} . \mathrm{g}-1$ & $0.197 \pm 0.009$ & $0.15 \pm 0.01$ \\
\hline $\mathrm{CaO}$ & $320 \pm 60$ & \\
$\mathrm{ZnO}$ & $100 \pm 10$ & $378 \pm 60$ \\
$\mathrm{Ga}_{2} \mathrm{O}_{3}$ & $70 \pm 4$ & $98 \pm 8$ \\
$\mathrm{ZrO}$ & $120 \pm 6$ & $76 \pm 10$ \\
$\mathrm{SrO}$ & $10 \pm 1$ & $70 \pm 5$ \\
\hline
\end{tabular}

\section{Conclusions}

The conditions applied in the irradiation range (20-150 kGy) of gamma rays and EB were not sufficient to alter the structure of the catalyst, which is demonstrated in ATR-FTIR spectra and verified with SEM.

Using irradiation to facilitate the removal (meaning the catalyst regeneration) of nickel contaminant, a major contaminant of the FCC catalyst, whether to rupture the crystalline structure (meaning the future reutilization of chemical elements present in the catalyst) is not possible in those irradiation conditions, as the EDXFRS data present.

The EDXFRS analysis also gives important information about the transformation that occurs in virgin catalyst after used (exhausted) in refineries, it is possible to assert that some aluminum molecules are 
lost during the process, when the percentage about $61 \%$ reach about $45 \%$ the catalyst is considered exhausted, while other contaminants blocks reactive catalyst sites as well as damages in it structure.

However, in view of these conditions, some authors have used irradiation for chain cracking reaction $[5,6]$. Then, one beneficial factor is the understanding that irradiation in crude oil context does not affect the catalyst structure, which could be used in refineries without interfering the catalyst performance.

\section{Suggestions for future Works}

$\mathrm{Ni}(\mathrm{Co})-\mathrm{Mo} / \mathrm{Al}_{2} \mathrm{O}_{3}$ catalyst is also used in the crude-oil processing, in a stage called HCC (Hidro catalytic Cracking), the presence of Molybdenum and Cobalt adds high value to the catalyst.

The use of $\mathrm{Ni}(\mathrm{Co})-\mathrm{Mo} / \mathrm{Al}_{2} \mathrm{O}_{3}$ catalystisan example of material that, after thoroughly characterized, became framed as hazardous waste from the late 90's. This situation was maintained in their view published by the EPA (Environmental Protection Agency) in September 2004 [7].

When studying EB with higher energies is possible to induce the decomposition of supported $\mathrm{Ni}(\mathrm{Co})-\mathrm{Mo} / \mathrm{Al}_{2} \mathrm{O}_{3}$ sulfide catalyst and organic fragments of hydrogenation catalyst wastes and also recovery of noble materials such as cobalt and molybdenum [8], as well as, the study of catalyst impregnated with coke from the crude oil distillation on an industrial scale.

To evaluate and comprehend the crystalline structures of $\mathrm{Ni}(\mathrm{Co})-\mathrm{Mo} / \mathrm{Al}_{2} \mathrm{O}_{3}$ and also $\mathrm{FCC}$ catalysts after gamma rays and electron beam irradiation, it will be necessary to carry out XRD (X-Ray Diffraction).

For the FCC catalyst a feasibility study will be made to understand if the extraction of silica or an addition of aluminum would alter the reactivity of the exhausted catalyst once the percentage of aluminum and silica reaches the virgin percentage.

\section{References}

[1] QU, Z., YAN, N., JIA, J., and WU, D. 2007. "Removal of Dibenzothiophene from Simulated Petroleum by Integrated Gamma-Irradiation and Zr/Alumina Catalyst." Applied Catalysis B: Environmental 71: 108-15.

[2] ABADIE, E. 2002. Processo de Refino. Material compilado pela Petrobrás, Curitiba.

[3] MITCHELL, B. R. 1980. "Metal Contamination of Cracking Catalysts." Ind. Eng. Chem. Res. Dev. 19 (2): 209-13.

[4] Cerqueira, H. S., CAEIRO, G., COSTA, L., and RIBEIRO, F. R. 2008. "Deactivation of FCC Catalysts." Journal of Molecular Catalysis A: Chemical 292 (1): $1-13$.

[5] MIRKIN, G., ZAYKINA, R. F., and ZAYKIN, Y. A. 2003. "Radiation Methods for Upgrading and Refining of Feedstock for Oil Chemistry." Radiation Physics and Chemistry 67 (3-4): 311-4.

[6] ZAYKIN, Y. A., ZAYKINA, R. F., and MIRKIN, G. 2003. "On Energetics of Hydrocarbon Chemical Reactions by Ionizing Irradiation.” Radiation Physics and Chemistry 67 (3): 305-9.

[7] AFONSO; J. C., SIlva, N., SAlvato, G. N., and BUSNARDO, R. G. 2006. "Recuperação de metais de catalisadores de hidrorrefino usados via fusão com $\mathrm{KHSO}_{4}$." Quim. Nova 29 (4): 856-61.

[8] SOlOVETSKII, YU. I., PANTELEEV, D. M., and LUNIN, V. V. 1998. "High-Temperature Electron Irradiation and Radiation-Thermal Technology for Utilization, Purification and Production of Some Metals." Radiation Physics Chemistry 52 (1-6): 659-64. 